MATEC Web of Conferences 9, 02006 (2013)

DOI: $10.1051 /$ matecconf/20130902006

(C) Owned by the authors, published by EDP Sciences, 2013

\title{
Calculation of radiant heat flux from compartment fires in various ventilation conditions
}

\author{
Devin Glennie ${ }^{a}$ and George Hadjisophocleous
}

Carleton University Ottawa, Ontario, Canada

\section{INTRODUCTION}

Radiant heat flux calculation methods from a compartment fire to an adjacent structure have been previously developed using different techniques [1-7]. All of these methods consider post-flashover, ventilation controlled compartment fire scenarios where internal compartment temperatures and external flames through openings contribute to the overall radiation received at the target locations. However, the applicability of these methods for compartments with different ventilation conditions such as fuel controlled or forced-flow ventilation is unknown due to insufficient experimental data. These conditions may be necessary for design scenarios where wind conditions can affect burning in the room and the resulting heat transfer to adjacent buildings. New data from large-scale compartment fire tests is used in this paper to explore the development of calculation methods for different ventilation conditions.

\section{TEST COMPARTMENT}

A single room compartment $4 \mathrm{~m} \times 3 \mathrm{~m} \times 2.75 \mathrm{~m}$ high was used for testing and a schematic is shown in Figure 1. The compartment contained an adjustable window opening in the wide front face $3 \mathrm{~m} \times 1.5 \mathrm{~m}$ high which could be decreased in size to $1 \mathrm{~m} \times 1 \mathrm{~m}$. The front face of the compartment extended above the window to approximately 5 meters in height. A series of propane burners were distributed across the compartment $10 \mathrm{~cm}$ from the floor to provide propane fuel for the fire. Additional fresh air could be provided to the compartment with forced flow through small ports in the rear of the test compartment.

\section{INSTRUMENTATION}

Temperatures in the compartment were recorded with five thermocouples in the room, three thermocouples spaced horizontally along the window soffit, and three thermocouples spaced at $0.5 \mathrm{~m}$ intervals vertically above the window centre. A target wall, shown in Figure 2, was placed opposite the compartment 3 or 5 meters away. Gardon gauges were distributed across the face of the target wall at $0.5 \mathrm{~m}$ intervals to provide measurements of heat flux opposite the face of the window and to a height of $1.5 \mathrm{~m}$ above the window opening. An infrared camera was also used to collect additional temperature measurements of the compartment, external flames, and the target wall during the tests.

The heat release rate in the fire tests was determined separately by measuring the mass flow rate of propane to the burners and also through oxygen consumption calorimetry of the exhaust gases.

ae-mail: devinkglennie@gmail.com

This is an Open Access article distributed under the terms of the Creative Commons Attribution License 2.0, which permits unrestricted use, distribution, and reproduction in any medium, provided the original work is properly cited. 


\section{MATEC Web of Conferences}

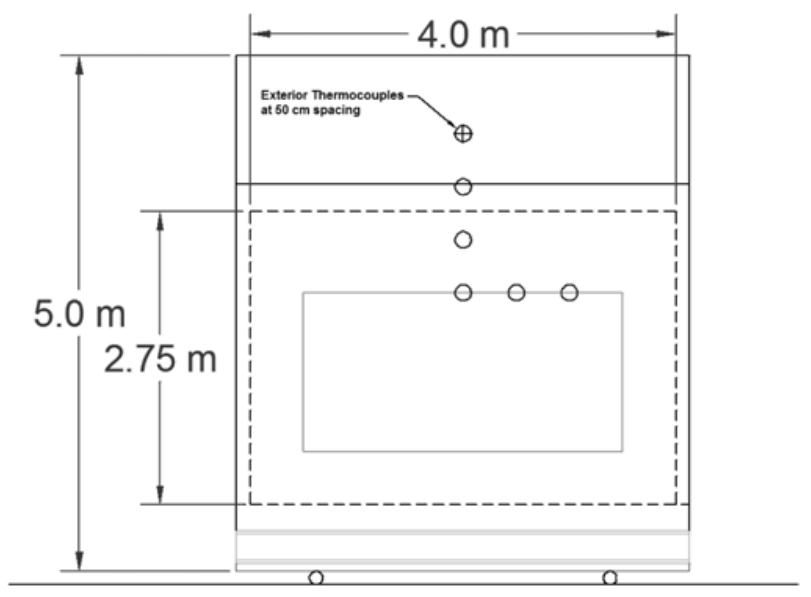

Figure 1. Schematic diagram of the front face of the compartment showing maximum window size.

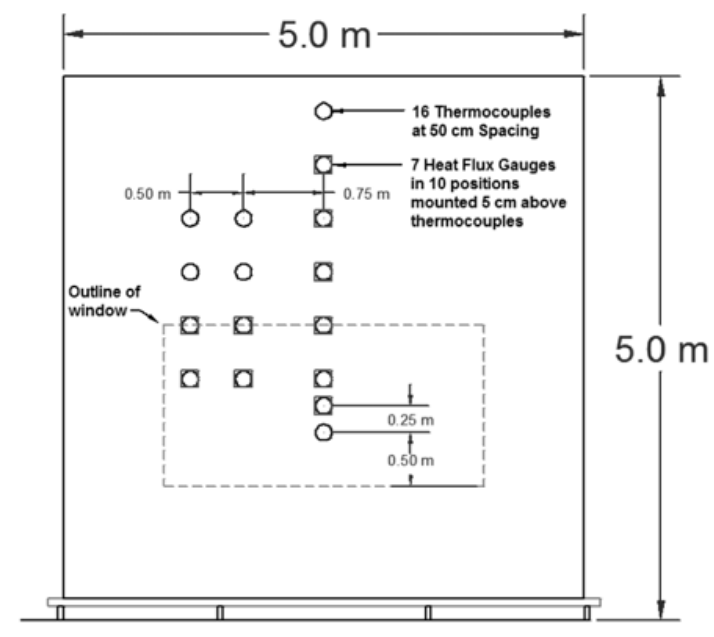

Figure 2. Schematic diagram of target wall showing sensor locations and outline of the compartment window opposite the wall.

\section{FIRE TESTS}

Tests were conducted using a total of six different window sizes and four different flow rates of air. Propane flow rates to the fires were manually adjusted to simulate fuel controlled and ventilation controlled burning in the compartment. Peak heat release rates in the compartment ranged from 1 to $5 \mathrm{MW}$. Forced flow through the rear of the compartment was employed in some tests. Approximately 20 separate tests were conducted with typical tests lasting between 15 and 20 minutes, which allowed for conditions to reach steady state. Tests were terminated when sufficient infrared imaging and other data was captured. Most window configurations were run only for two tests: one ventilation controlled and one fuel controlled. Two different window sizes were employed during the forced flow scenarios. A photograph showing the compartment, external flaming, and the target wall during a test is shown in Figure 3. 


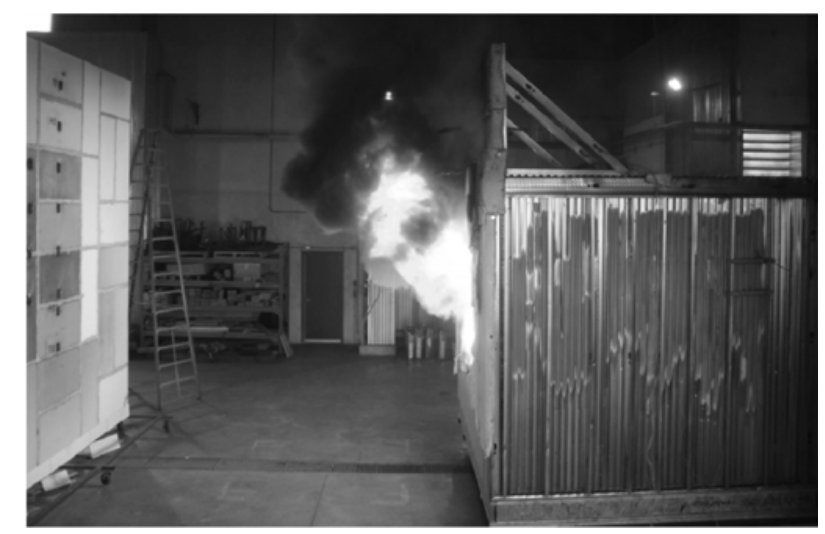

Figure 3. Photograph of compartment profile during a test.

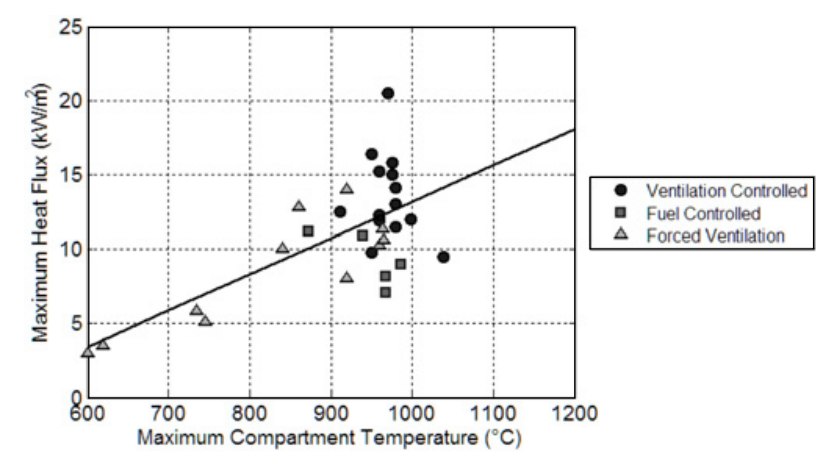

Figure 4. Maximum received heat flux recorded and the internal compartment temperature.

\section{EXPERIMENTAL RESULTS}

Looking at all the tests in the series, a loose correlation is observed between the maximum interior compartment temperature and the maximum heat flux measured in each test as shown in Figure 4 . The correlation becomes tighter when comparing temperatures at the window recorded through infrared imaging. This is shown in Figure 5 which is plotted for all tests regardless of window size, fire size, or whether the fire was under or over ventilated. This result illustrates that internal gas temperature alone is not sufficient to estimate radiation from a window emitter and that a portion of the exterior flaming in front of the window must be considered.

Using the temperature of the opening measured with the infrared camera and a rectangular radiator equal to the window area, the presumed radiation emitted in front of the opening was separated from the overall maximum measured values. The remaining portion of the measure heat flux is radiation received from the extrusive and external flames and all other sources. For the ventilation controlled fires, this value was generally around $40 \%+/-12 \%$ of the maximum received radiation. For the fuel controlled fires, which had less exterior burning, this value was still similar at $40 \%+/-7 \%$. When the fuel flow was increased to the compartment and the fire became further under-ventilated, the room temperature increased along with an increase in external flaming due to excess unburned fuel leaving the compartment. This provided a sizable increase in the received radiation and is illustrated in Figure 6 for tests conducted with a $1.45 \times 1.14 \mathrm{~m}$ high window. Increasing the propane flow rates in these tests nearly doubled the received radiation due to increased exterior flaming. 


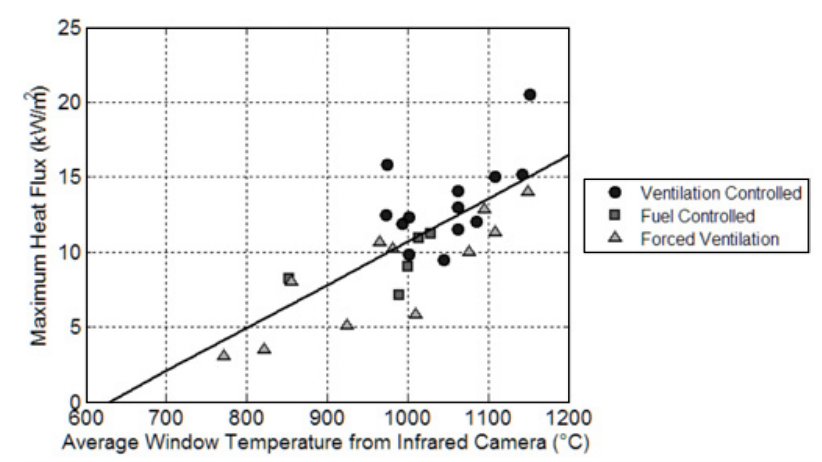

Figure 5. Maximum received heat flux recorded and the average temperature over the front face of the window.

Similarly, when forced ventilation was provided to the compartment, exterior flaming decreased as did the percentage of radiation from the flames. This is as shown in Figure 7 for the same window configuration as Figure 6. The effect of increased ventilation to the compartment was observed to be a net increase in the measured radiation though the difference was less than $10 \%$ higher than the no flow configuration. However, if severely over ventilated, compartment cooling increases and less radiation is received at the target location. The total radiation in Figure $8 \mathrm{~b}$ is just $3 \mathrm{~kW} / \mathrm{m}^{2}$ versus the $10 \mathrm{~kW} / \mathrm{m}^{2}$ reported for the test in Figure $8 \mathrm{a}$. For the smaller fires shown in profile in Figure 8 , the effect of the additional momentum from the forced flow also caused changes to the flame projection from the compartment. This was only significantly observed in one test where external flaming and a large momentum imbalance were present. This deflected the plume enough to cause direct smoke impingement onto the target wall. For this fire test, the calculated radiation emitted from the compartment opening varied drastically between sensors with upwards of 20 to $30 \%$ variance between the different heat flux sensors in the same test. This is thought to be due to the changes in flame projection and due to the impingement.

To estimate the variance between the test data, one window size and test configuration was tested three times. Comparison of heat flux values between these tests showed a variance of $7 \%$ between the maximum heat flux levels received. Part of this variation is due to the propane flow rate during the test which varied as much as $5 \%$ due to manual manipulation of the propane supply valve. However, similar tests performed on different days (one on Feb. 24 and one on July 8) showed a difference of approximately $2 \mathrm{~kW} / \mathrm{m}^{2}$ (20\% of the measured values). The difference in ambient temperatures in the unheated fire test lab on these two dates and additional heat loss to the surroundings appears to account for the discrepancy. Additional sources of error in the experiments include convection transfer to the sensor and from the heated target wall. This is likely to attribute as much as $10 \%$ difference from the calculated results. It can be seen in the Figure $8 \mathrm{~b}$ that there is $1.4 \mathrm{~kW} / \mathrm{m}^{2}$ of measured radiation which is not accounted for from the window emitter though there is no external flaming from the compartment. The likely source of this radiation is one of those previously discussed or from radiation through the compartment wall itself. This sample establishes the lower error bound on the experimental values presented here.

\section{RADIATION HEAT FLUX CALCULATION METHODS}

Though it may be more practical to use CFD or other computer modelling to calculate the radiation received at a target location, it is still general practice to use hand calculations for some design considerations in fire safety if not only for a first run approximation. The remainder of this paper focuses 
$1^{\text {st }}$ International Seminar for Fire Safety of Facades, Paris (France), 2013

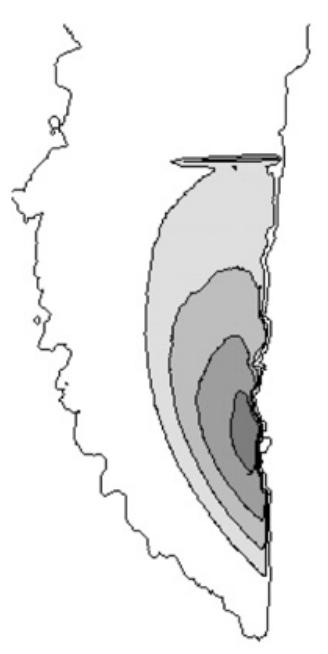

(a) 2.5 MW Fire Size Flame Radiation $=6.6 \mathrm{~kW} / \mathrm{m}^{2}$

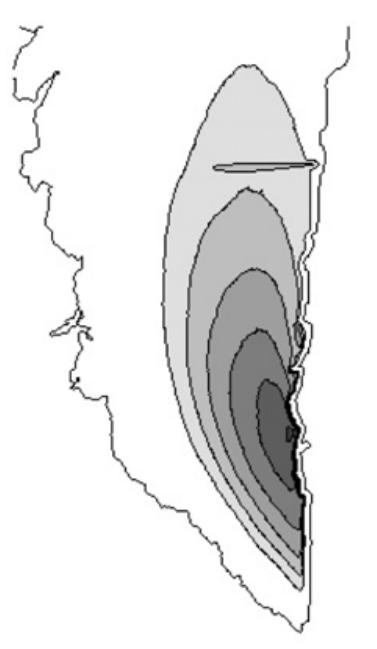

(b) 3.0 MW Fire Size Flame Radiation $=8.1 \mathrm{~kW} / \mathrm{m}^{2}$

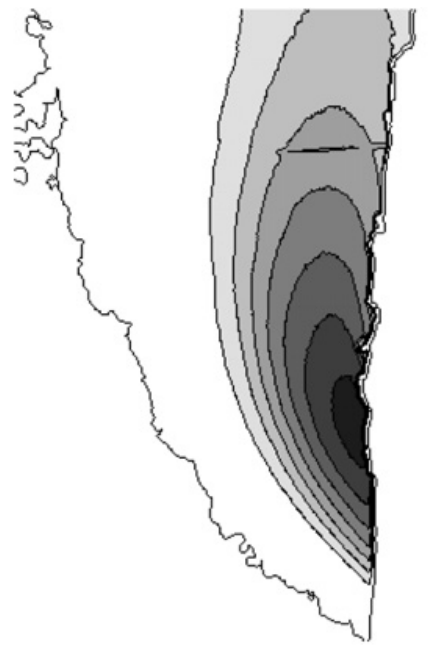

(c) 3.6 MW Fire Size Flame Radiation $=9.5 \mathrm{~kW} / \mathrm{m}^{2}$

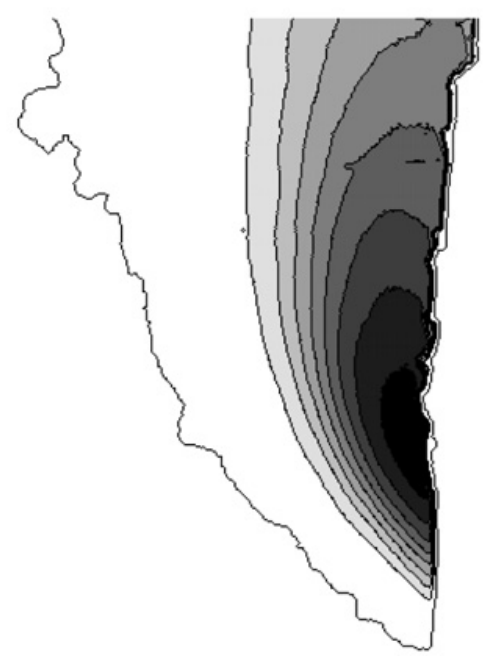

(d) 4.0 MW Fire Size Flame Radiation $=12 \mathrm{~kW} / \mathrm{m}^{2}$
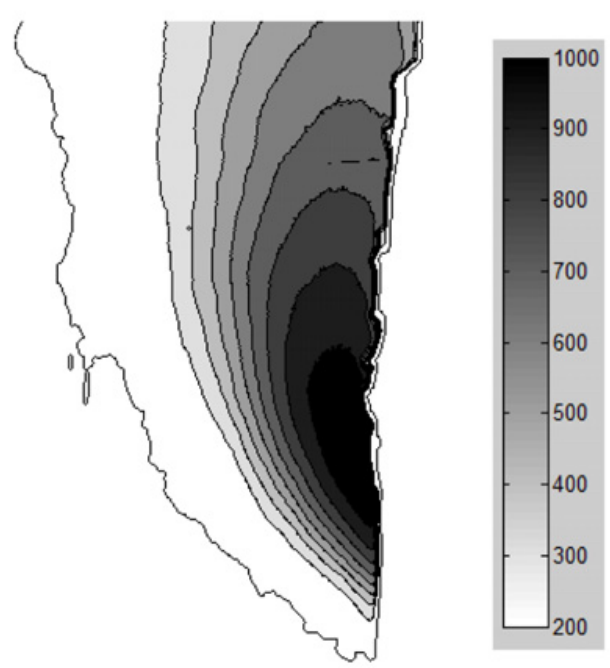

(e) 4.5 MW Fire Size Flame Radiation $=12 \mathrm{~kW} / \mathrm{m}^{2}$

Figure 6. Flame radiation and temperature profile for fires of increasing size for a $1.45 \mathrm{~m} \times 1.14 \mathrm{~m}$ tall window.

on radiation heat flux calculation methods which could be completed by hand or implemented in a spreadsheet.

There are two different approaches to determining the radiation received from the extrusive and external flames. Similar to the window emitter, the flame can be modelled as vertical plane as has been done by Law (1978) [1], Oleszkiewicz (1989) [2], Lin (2000) [3], Cheng and Hadjisophocleous (2012) [7], and Chen and Francis (2002) [4]. Chen and Francis also examined the alternative approach which is to treat the flame as a point source which was also implemented by Himoto (2008) [5] for an urban fire spread model. This latter model was not implemented in full and temperatures in the compartment were taken from the experimental data and pressure profiles estimated. References [1-3], and [4] each use the 
MATEC Web of Conferences

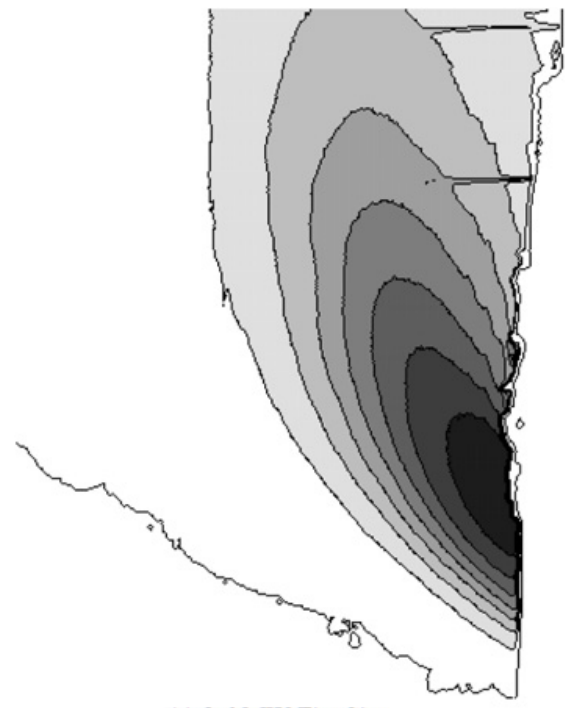

(a) 3.6 MW Fire Size

Forced flow at $0.3 \mathrm{~kg} / \mathrm{s}$

Flame Radiation $=7.0 \mathrm{~kW} / \mathrm{m}^{2}(69 \%$ of $\max )$

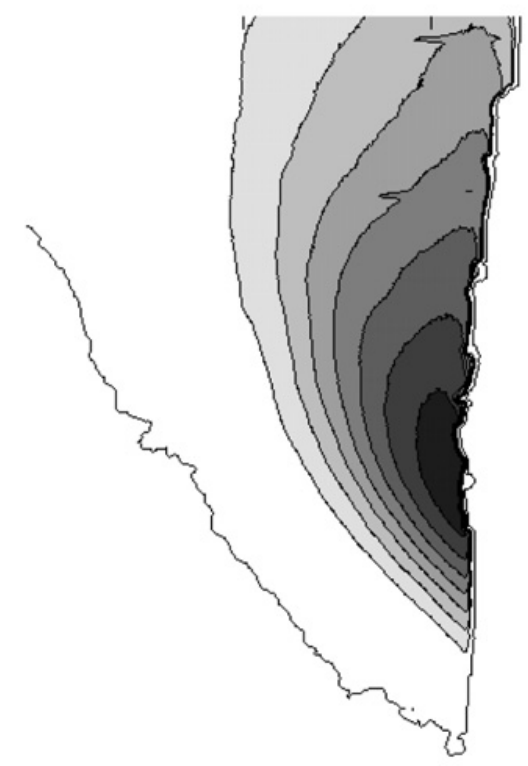

(c) 3.6 MW Fire Size

Forced flow at $0.9 \mathrm{~kg} / \mathrm{s}$

Flame Radiation $=7.2 \mathrm{~kW} / \mathrm{m}^{2}(63 \%$ of $\max )$

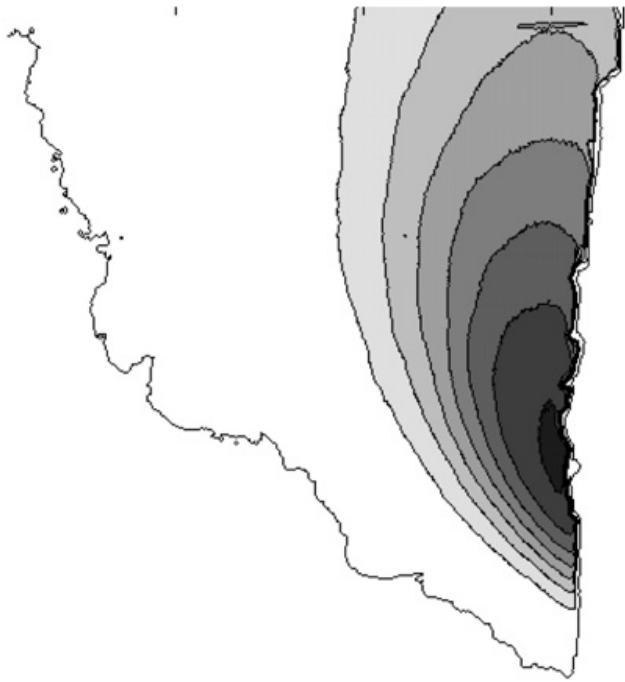

(b) 3.6 MW Fire Size

Forced flow at $0.6 \mathrm{~kg} / \mathrm{s}$

Flame Radiation $=5.3 \mathrm{~kW} / \mathrm{m}^{2}(66 \%$ of $\max )$
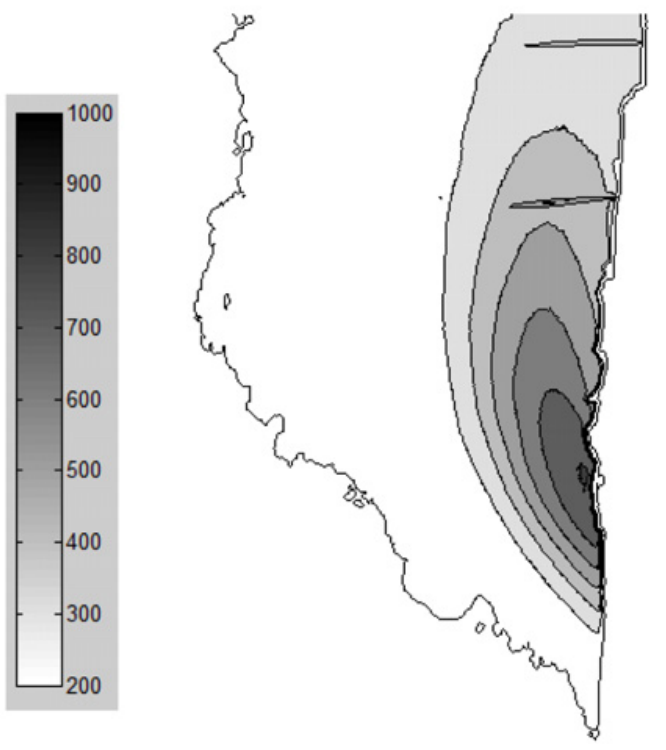

(d) 3.6 MW Fire Size

Forced flow at $1.8 \mathrm{~kg} / \mathrm{s}$

Flame Radiation $=5.7 \mathrm{~kW} / \mathrm{m}^{2}(50 \%$ of $\max )$

Figure 7. Flame radiation and temperature profiles for fires with increasing ventilation for a $1.45 \mathrm{~m} \times 1.14 \mathrm{~m}$ tall window.

same principle equations to determine the flame radiation though [1,2], and [3] all have slightly different executions. The area method presented by Chen and Francis is the same as Law and is not presented separately. Lin has presented an area method similar to Law but the dimensions of the extrusive flame have been calculated differently. 


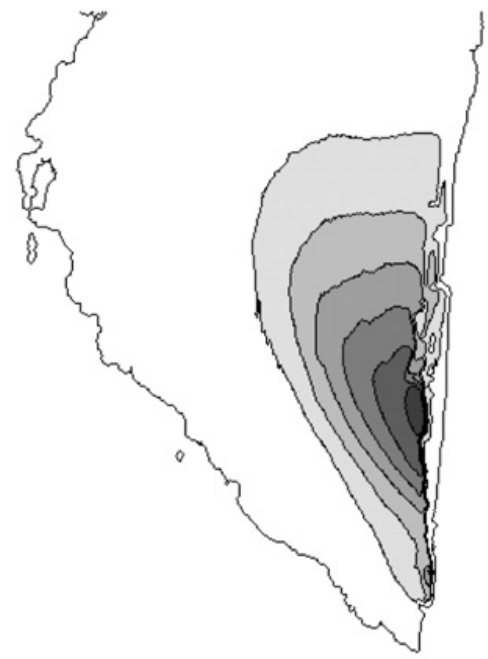

(a) 1.5 MW Fire Size

$$
\text { No Forced ventilation }
$$
Flame Radiation $=5.6 \mathrm{~kW} / \mathrm{m}^{2}$

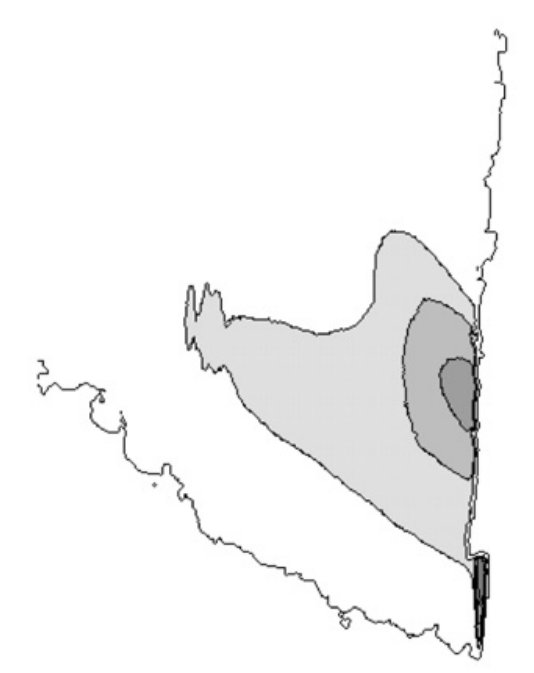

(d) 2.5 MW Fire Size Forced flow at $1 \mathrm{~kg} / \mathrm{s}$ Flame Radiation $=5.2 \mathrm{~kW} / \mathrm{m}^{2}$

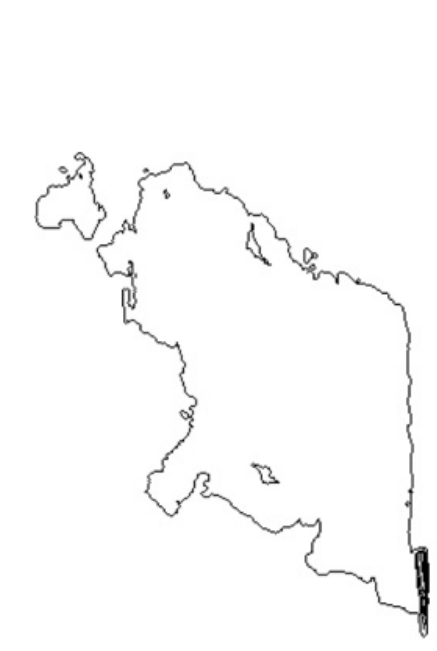

(b) 1.5 MW Fire Size

Forced flow at $1 \mathrm{~kg} / \mathrm{s}$ Flame Radiation $=1.4 \mathrm{~kW} / \mathrm{m}^{2}$

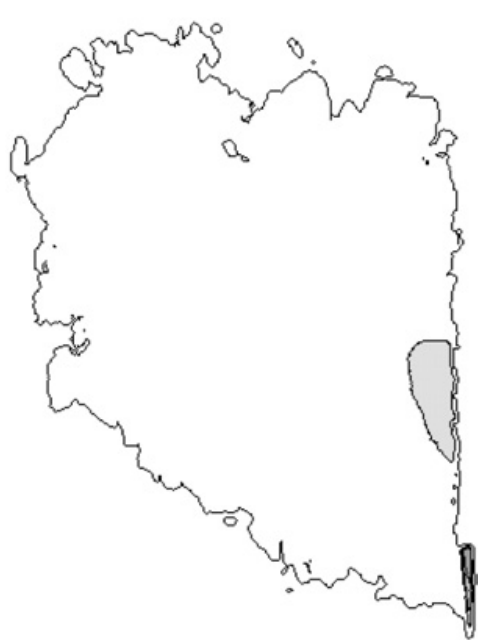

(c) 2.0 MW Fire Size

Forced flow at $1 \mathrm{~kg} / \mathrm{s}$ Flame Radiation $=1.9 \mathrm{~kW} / \mathrm{m}^{2}$
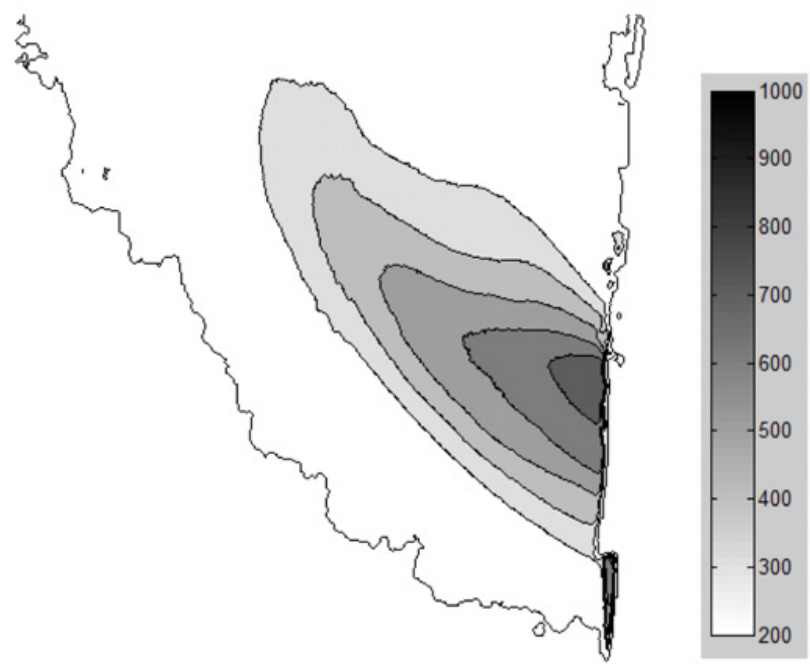

(e) 3.0 MW Fire Size

Forced flow at $1 \mathrm{~kg} / \mathrm{s}$ Flame Radiation $=8.1 \mathrm{~kW} / \mathrm{m}^{2}$

Figure 8. Flame radiation and temperature profiles for fires with increasing fuel flow rate and two $0.5 \mathrm{~m} \times 1.0 \mathrm{~m}$ tall windows.

Law's implicitly presents a method to calculate radiation from fires with forced draft and Himoto's method can be adapted (through the use of pressure profiles and mass flow rates of air) to estimate this effect as well.

As already stated, the main approach to calculate radiation from a window emitter is to assume it emits as a flat plane at the window location at some internal gas or other temperature. This is employed for each of the models compared here though the temperature source used for Cheng and Hadjisophocleous is different.

Some of the main features of the models are summarized in Table 1. 
MATEC Web of Conferences

Table 1. Summary of different calculation procedures.

\begin{tabular}{|c|c|c|c|}
\hline Reference & Flame Radiator Shape & Burning Regime & $\begin{array}{l}\text { Window Emitter } \\
\text { Temperature }\end{array}$ \\
\hline [1] - Law (1978) & $\begin{array}{l}\text { Rectangular Area - } \\
\text { constant flame } \\
\text { thickness }\end{array}$ & $\begin{array}{l}\text { Ventilation or fuel } \\
\text { controlled and forced } \\
\text { flow }\end{array}$ & $\begin{array}{l}\text { Internal compartment } \\
\text { gas temperature }\end{array}$ \\
\hline $\begin{array}{l}\text { [2] - Oleszkiewicz } \\
(1989)\end{array}$ & $\begin{array}{l}\text { Triangular Area - } \\
\text { emissivity decreases } \\
\text { with height }\end{array}$ & Ventilation controlled & $\begin{array}{l}\text { Internal compartment } \\
\text { gas temperature }\end{array}$ \\
\hline $\begin{array}{l}{[7] \text { - Cheng and }} \\
\text { Hadjisophocleous } \\
\text { (2012) }\end{array}$ & $\begin{array}{l}\text { Rectangular Area - } \\
\text { constant flame } \\
\text { thickness }\end{array}$ & Ventilation controlled & $\begin{array}{l}\text { Flame temperature } \\
\text { at soffit }\end{array}$ \\
\hline $\begin{array}{l}\text { [4] - Chen and Francis } \\
\text { (2002) }\end{array}$ & Point Source & Ventilation controlled & $\begin{array}{l}\text { Internal compartment } \\
\text { gas temperature }\end{array}$ \\
\hline [5] - Himoto (2008) & Point Source & $\begin{array}{l}\text { Ventilation controlled or } \\
\text { fuel controlled }\end{array}$ & $\begin{array}{l}\text { Internal compartment } \\
\text { gas temperature }\end{array}$ \\
\hline [3] - Lin (2000) & $\begin{array}{l}\text { Rectangular - based on } \\
\text { Hasemi flame height }\end{array}$ & Burning against a wall & $\begin{array}{l}\text { Internal compartment } \\
\text { gas temperature }\end{array}$ \\
\hline
\end{tabular}

Table 2. Average error for each calculation method.

\begin{tabular}{lccc}
\hline \multicolumn{1}{c}{ Method } & Average Error & \\
& Ventilation Controlled & Fuel Controlled & Forced Ventilation \\
\hline [1] - Law (1978) & $60 \%$ & $59 \%$ & $42 \%$ \\
[2] - Oleszkiewicz (1989) & $69 \%$ & $68 \%$ & $37 \%$ \\
[7] - Cheng & $45 \%$ & $47 \%$ & $59 \%$ \\
Hadjisophocleous (2012) & & & \\
[4] - Chen and Francis (2002) & $51 \%$ & $44 \%$ & $36 \%$ \\
[5] - Himoto (2008) & $31 \%$ & $39 \%$ & $39 \%$ \\
[3] - Lin (2000) & $26 \%$ & $16 \%$ & $57 \%$ \\
\hline
\end{tabular}

\section{COMPARISON TO EXPERIMENTAL DATA AND DICUSSION}

Plots of the measured heat flux versus the maximum calculated heat flux for each method are shown in Figure 9. For those methods without explicit direction to deal with fuel controlled or forced ventilation, the calculations were performed for comparison while ignoring these effects. Comparing the data, all of the methods tended to significantly underestimate the measured heat flux recorded during the compartment tests and some do not show any agreement or correlation at all to the different experimental parameters. Average error rates compared to the measured values are shown in Table 2.

The lowest average error rate for ventilation and fuel controlled fires came from Lin [3] which contains a relatively simple approach. The extrusive flame is assumed to be continuous with a flame burning in the compartment and the combined flame height and temperature of both are calculated. The only difficultly in implementing this method is the subdivision of the flame into regions with different areas and different view factors. Himoto's method [5] also gave low error rates but is much harder to implement due to the need for pressure profiles and calculation of the neutral plane. It would be close in sophistication to a computational zone model to implement in full. The pressure profile, however, can be estimated to speed up the computational time. Both of these methods also require the internal compartment temperature to calculate the portion of radiation from the window emitter. 
$1^{\text {st }}$ International Seminar for Fire Safety of Facades, Paris (France), 2013
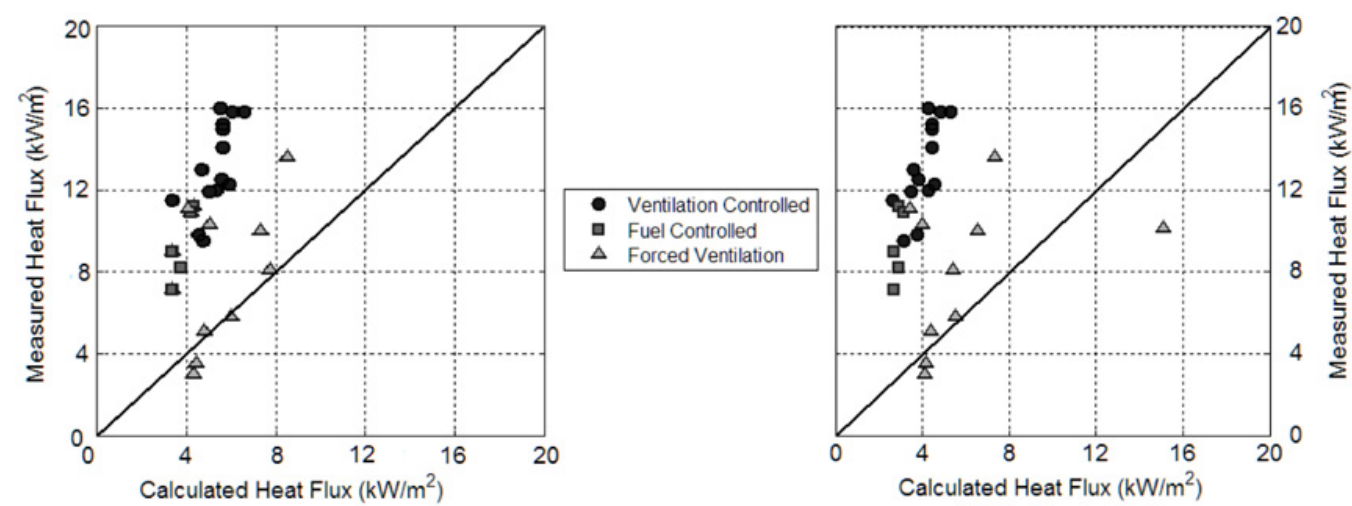

(a) Law (1978)
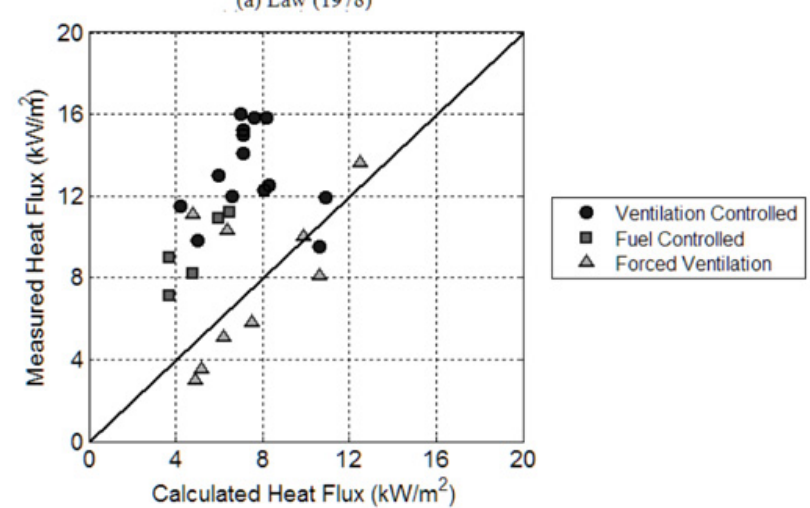

(c) Cheng and Hadjisophocleous (2012)
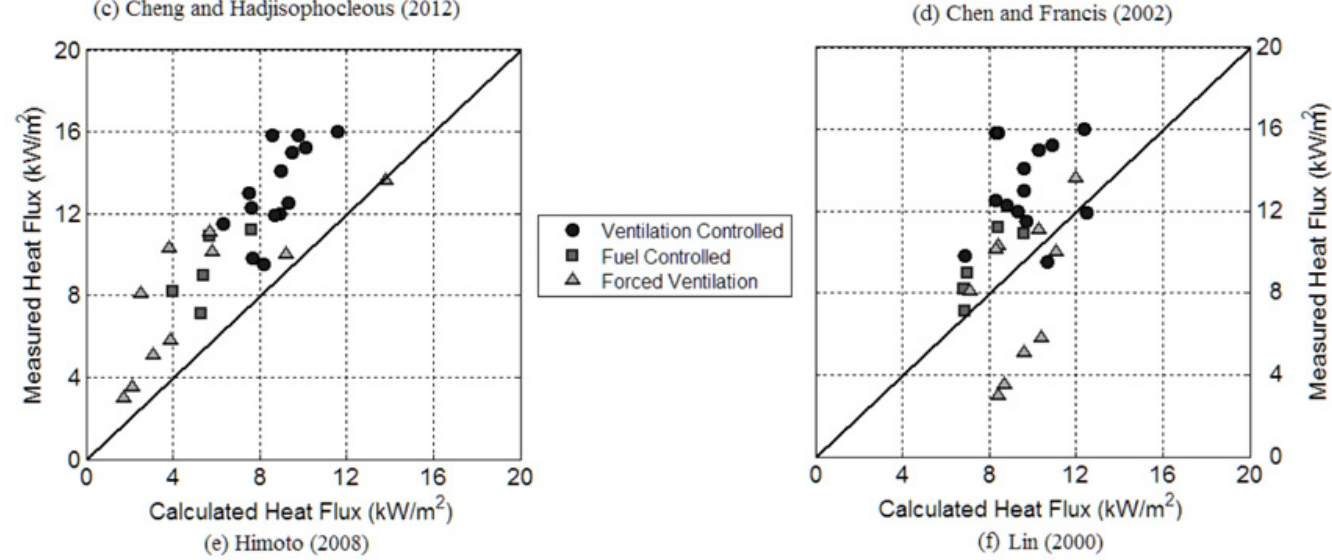

(f) $\operatorname{Lin}(2000)$

Figure 9. Comparison of measured and calculated radiation heat flux for six different methods.

Though they are similar, Cheng and Hadjisophocleous's method [7] outperformed Oleszkiewicz's [2] and Law's [1]. The main differences between these methods are the values used for the window emitter temperature and for emissivity in the flame radiation calculation. Use of the flame temperature under the soffit, such as Cheng and Hadjisophocleous did, proves to be useful for this calculation and agrees with experimental results in which temperatures from infrared images of the window face were higher than those recorded inside the compartment.

The largest unknown for these calculations is the emissivity used. Though values were obtained for propane flames, these appear to be too low to accurately capture the external flame. Part of this is due to 


\section{MATEC Web of Conferences}

the extra soot in the flame as it exits the compartment after burning in under-ventilated conditions. Cheng and Hadjisophocleous estimated the emissivity for this type of flame in his work and it was, at some times, double that which the other models considered. Oleszkiewicz's model for emissivity produced the lowest calculated heat fluxes and, although novel in its approach, was not suitable for calculations to adjacent targets. As well, Lin [3] did not specify what emissivity to use so the method of Cheng and Hadjisophocleous was also used for those calculations. This may also explain why the calculated heat fluxes from Lin were generally higher.

For forced ventilation, none of the methods presented were particularly good at predicting the measured heat flux. This underlines the difficulties in trying to capture all the dynamic effects taking place when additional ventilation is introduced into a compartment. More ventilation causes more burning in the compartment which reduces external flaming and causes higher compartment temperatures and higher received radiation. However, too much ventilation can eliminate the external flame altogether, cause additional compartment cooling, and reduce the levels of received radiation.

\section{CONCLUSIONS AND RECOMMENDATIONS}

Although different methods exist to calculate the radiation received from a compartment fire to an adjacent structure, these methods have considerable difficulty in predicting experimentally measured heat fluxes. Both area and point source methods seem to give reasonably the same results. However, to use an area method for predicting radiation from a flame, the emissivity of the exiting flame is one area where considerable attention needs to be focused.

At this time, there is still insufficient data to accurately formulate a calculation procedure when forced ventilation in involved. However, the method presented by Law is a good starting point for future consideration. It is also theorized that the procedure for calculating flame height suggested by Lin could be modified to include flame deflection in forced ventilation scenarios or refined for use with a point source method to eliminate some of the calculation difficulty.

Recommended calculation procedures are as follows:

1. For calculation of heat flux in ventilation or fuel controlled scenarios:

Himoto or Lin's method may be used. Care must be taken to choose an appropriate emissivity for the flame for Lin's method. Cheng and Hadjisophocleous's values for emissivity are more conservative than other methods.

2. For calculation of heat flux from compartments with significant forced ventilation, no strong hand calculations currently exist at this time. Computer modelling is the best approach for this scenario. However, if the ventilation to the compartment is weak or the adjacent structure sufficiently far away to prevent smoke impingement, the heat flux at the target location may be estimated assuming a ventilation or fuel controlled scenario.

\section{References}

[1] Law, M., "Fire Safety of External Building Elements - The Design Approach", Engineering Journal of the American Institute of Steel Construction, Second Quarter, 59-74, 1978.

[2] Oleszkiewicz, I., "Heat Transfer From a Window Fire Plume to a Building Façade", National Research Council Canada Institute for Research in Construction, IRC Paper No. 1662., Ottawa, Canada, 1989.

[3] Lin, C.Y., "Study of Exposure Fire Spread Between Buildings by Radiation", Journal of the Chinese Institute of Engineers, 23(4), 493-504, 2000.

[4] Chen, A. and Francis, J., "Radiant heat flux to external surfaces from escaping and extrusive flashover flames", Proceedings of the Institution of Mechanical Engineers Part C - Journal of Mechanical Engineering Science, 217(2), 247-256, 2002. 
$1^{\text {st }}$ International Seminar for Fire Safety of Facades, Paris (France), 2013

[5] Himoto, K. and Tanaka, T., "Development and validation of a physics-based urban fire spread model”, Fire Safety Journal, 43, 477-494, 2008.

[6] Lee, Y. P., Delichatsios, M. A., Ohmiya, Y., Wakatshuki, K., Yanagisawa, A., and Goto, D., "Heat fluxes on opposite building wall by flames emerging from an enclosure", Proceedings of the Combustion Institute, 32, 2551-2558, 2009.

[7] Cheng, H. and Hadjisophocleous, G. V., "Experimental study and modelling of radiation from compartment fires to adjacent buildings", Fire Safety Journal, 53, 43-62, 2012. 